\title{
Osteopontin in Vascular Calcification: A Central Player or Accidental Witness?
}

\author{
Alexander E Berezin ${ }^{1,2 *}$ \\ ${ }^{1}$ Consultant of Therapeutic Unit, Private Hospital "Vita Center", 3, Sedova str., Zaporozhye, Ukraine \\ ${ }^{2}$ Consultant of Therapeutic Unit, Internal Medicine Department, State Medical University, 26, Mayakovsky av., Zaporozhye, Ukraine
}

\begin{abstract}
Osteopontin (OPN) is an integrin-binding ligand belonged to the family of $\mathrm{N}$-linked glycoprotein, which is produced by activated mononuclears and linking systemic inflammation, atherosclerosis, and vascular remodeling. There is a large body of evidence regarding the controversial role of OPN in vascular calcification, while OPN is considered a pretty accurate biomarker of vascular remodeling with promising predictive value for cardiovascular (CV) disease and CV events. The short communication depicts the discussion about some controversies regarding exclusive role of OPN in several phases of vascular remodeling.
\end{abstract}

Keywords: Hypertension; Vascular remodeling; Inflammation; Calcification; Osteopontin; Regulation

\section{Osteopontin in Vascular Calcification}

Recent preclinical and clinical studies have shown that vascular calcification is inexorable pathological process leading to mechanical rigidity and stiffness of vascular wall, endothelial dysfunction, development and accelerating atherosclerosis even in the absence of established cardiovascular (CV) disease [1-3]. Ectopic calcification is represented by several mutually counteracting molecular mechanisms, i.e., oxidative stress, microvascular inflammation, immune cell-to-cell cooperation, accumulation of lipids and extracellular proteins, vascular reparative systems, and metabolic disorders [4-6]. All these processes are under tight regulation of vitamin $\mathrm{D}$, parathyroid hormone-related peptides (fibroblast growth factor, transcription factor Sox2, betacatenin, etc.) and matricellular proteins such as osteopontin (OPN) and phosphate [7-10].

OPN is an integrin-binding ligand belonged to the family of $\mathrm{N}$-linked glycoprotein, which is produced by activated mononuclears and linking systemic inflammation, atherosclerosis, and vascular remodeling via regulating ectopic calcification and extracellular matrix accumulation [11]. Indeed, OPN corresponded to hyperphosphatemia, conventional and nonconventional $\mathrm{CV}$ risk factors and $\mathrm{CV}$ disease mortality [10]. It has been postulated that OPN appeared to block vascular calcification most likely by preventing calcium phosphate crystal growth and inducing cellular mineral resorption. However, the role of OPN in vascular calcification is pretty controversial. The first controversy is based on opinion regarding that the OPN was found in elevated concentration in patients with established vascular calcification, atherosclerosis, and CV disease associated with severe vascular remodeling including hypertension, chronic kidney disease, diabetes mellitus $[4,9,12]$. In this context, OPN is an accurate biomarker of vascular remodeling closely relating to inflammation intensity, glucose level and pro-thrombotic state with promising predictive value for CV events [13].

However, there is large body of evidence that OPN could be an inducible inhibitor of vascular calcification in vivo and that the elevation of OPN level in serum reflects an involvement of protective mechanisms against ectopic calcium deposition [14]. Indeed, OPN deficiency may attenuate development and accelerating atherosclerosis increasing susceptibility to calcium deposition in smooth muscle cells $[15,16]$.

Second controversy relates to a widely known fact regarding that the OPN is strongly induced in mononuclear and myeloid cells acting as pro-inflammatory mediator of direct and indirect vascular injury leading to endothelial dysfunction $[9,17,18]$. Interestingly, exogenous OPN is able to inhibit a differentiation of activated macrophages into osteoclasts in vascular wall and attenuate shaping M2-phenotype of macrophages with anti-inflammatory ability [9]. Thus, mononuclears obtained from patients with and without established vascular calcification may reply to OPN in different way that confirms being alternatively shaping mononuclears in vascular wall during ectopic calcification. Probably, OPN exerts a pivotal role in turning M1 phenotype of macrophages into M2 phenotype in vascular calcification that coordinates reducing expression of several pro-inflammatory factors and attenuating vascular osteoclast formation.

The next controversy allows us considering about a cause of interrelationship between inflammatory cytokines, overproduction of reactive oxygen species and OPN expression in individuals with established CV diseases. Inflammatory-induced OPN through NADPH oxidase signaling cascade may regulate an activation of pro-matrix metalloproteinase 9 in aortic mesenchymal cells, which play a central role in vascular reparation [19] acting as endogenous repair system together endothelial progenitor cells [6]. Moreover, deficiency of OPN presentation in aorta associated with increased risk of aneurism formation, thrombosis and fissuring plaque cap [20]. Whether OPN is a primary regulator of exaggerated inflammation cascade in the target cells via control of proliferative response or non-specific messenger, which protects vascular wall against calcium deposition through blockage of tissue metalloproteinases is not fully understood. However, there is evidence that inhibition of OPN prevented vascular calcification [21]. How similar evidence relates to clinical findings regarding predictive value of circulating OPN in individuals with and without established $\mathrm{CV}$ diseases is not clear [22]. Large clinical studies are required in

*Corresponding author: Alexander E Berezin, Consultant of Therapeutic Unit Internal Medicine Department, State Medical University, 26, Mayakovsky av., Zaporozhye, Ukraine, Tel: +380612894585; E-mail: dr_berezin@mail.ru(or) aeberezin@gmail.com

Received March 29, 2017; Accepted April 12, 2017; Published April 17, 2017

Citation: Berezin AE (2017) Osteopontin in Vascular Calcification: A Central Player or Accidental Witness? Med Chem (Los Angeles) 7: 844-845. doi: 10.4172/21610444.1000439

Copyright: @ 2017 Berezin AE. This is an open-access article distributed under the terms of the Creative Commons Attribution License, which permits unrestricted use, distribution, and reproduction in any medium, provided the original author and source are credited. 
future to explain in details the role of OPN as a biomarker of $\mathrm{CV}$ events and CV diseases and as well as a possible target of medical care.

\section{Conclusion}

OPN is considered a multi-directed factor contributing in several phases of vascular remodeling including calcium accumulation, atherosclerosis, vascular reparation and microvascular inflammation. The role of OPN as a pretty accurate biomarker of $\mathrm{CV}$ risk, $\mathrm{CV}$ diseases and CV events are actively investigated, while there are several controversies in final effects of OPN regarding vascular calcification based on multimodal pathogenetic capabilities of the molecule. Future investigations are needed to understand the possible role of OPN in biomarker-guided therapy of the CV disease and assay of vascular remodeling risk.

\section{References}

1. Shao JS, Sierra OL, Cohen R, Mecham RP, Kovacs A, et al. (2011) Vascular calcification and aortic fibrosis: a bifunctional role for osteopontin in diabetic arteriosclerosis. Arterioscler Thromb Vasc Biol 31: 1821-1833.

2. Tesauro M, Mauriello A, Rovella V, Annicchiarico-Petruzzelli M, Cardillo C, et al. (2017) Arterial ageing: from endothelial dysfunction to vascular calcification. $\mathrm{J}$ Intern Med.

3. Berezin AE, Kremzer AA (2013) Circulating osteopontin as a marker of early coronary vascular calcification in type two diabetes mellitus patients with known asymptomatic coronary artery disease. Atherosclerosis 229: 475-481.

4. Berezin AE, Kremzer AA, Berezina TA, Martovitskaya YV (2016) The pattern of circulating microparticles in patients with diabetes mellitus with asymptomatic atherosclerosis. Acta Clin Belg 71: 38-45.

5. Aikawa E, Nahrendorf M, Figueiredo JL, Swirski FK, Shtatland T, et al. (2007) Osteogenesis associates with inflammation in early-stage atherosclerosis evaluated by molecular imaging in vivo. Circulation 116: 2841-2850.

6. Berezin AE (2016) Endothelial progenitor cells dysfunction and impaired tissue reparation: The missed link in diabetes mellitus development. Diabetes Metab Syndr.

7. Amizuka N, Davidson D, Liu H, Valverde-Franco G, Chai S, et al. (2004) Signalling by fibroblast growth factor receptor 3 and parathyroid hormonerelated peptide coordinate cartilage and bone development. Bone 34: 13-25.

8. Wolak T (2014) Osteopontin - a multi-modal marker and mediator in atherosclerotic vascular disease. Atherosclerosis 236: 327-337.
9. Ge Q, Ruan CC, Ma Y, Tang XF, Wu QH, et al. (2017) Osteopontin regulates macrophage activation and osteoclast formation in hypertensive patients with vascular calcification. Sci Rep 7: 40253

10. Giachelli CM, Speer MY, Li X, Rajachar RM, Yang H (2005) Regulation of vascular calcification: roles of phosphate and osteopontin. Circ Res 96: 717-722.

11. Cho HJ, Cho HJ, Kim HS (2009) Osteopontin: a multifunctional protein at the crossroads of inflammation, atherosclerosis, and vascular calcification. Curr Atheroscler Rep 11: 206-213.

12. Stepien E, Wypasek E, Stopyra K, Konieczynska M, Przybylo M, et al (2011) Increased levels of bone remodeling biomarkers (osteoprotegerin and osteopontin) in hypertensive individuals. Clin Biochem 44: 826-831.

13. Berezin AE (2016) Biomarkers for cardiovascular risk in patients with diabetes Heart 102: 1939-1941.

14. Speer MY, McKee MD, Guldberg RE, Liaw L, Yang HY, et al. (2002) Inactivation of the osteopontin gene enhances vascular calcification of matrix Gla proteindeficient mice: evidence for osteopontin as an inducible inhibitor of vascular calcification in vivo. J Exp Med 196: 1047-1055.

15. Matsui $Y$, Rittling SR, Okamoto $H$, Inobe M, Jia N, et al. (2003) Osteopontin deficiency attenuates atherosclerosis in female apolipoprotein E-deficient mice. Arterioscler Thromb Vasc Biol 23: 1029-1034.

16. Speer MY, Chien YC, Quan M, Yang HY, Vali H, et al. (2005) Smooth muscle cells deficient in osteopontin have enhanced susceptibility to calcification in vitro. Cardiovasc Res 66: 324-333.

17. Berezin AE, Kremzer AA, Berezina TA, Martovitskaya YV, Gronenko EA (2016) Data regarding association between serum osteoprotegerin level, numerous of circulating endothelial-derived and mononuclear-derived progenitor cells in patients with metabolic syndrome. Data Brief 8: 717-722.

18. Sage AP, Tintut Y, Demer LL (2010) Regulatory mechanisms in vascular calcification. Nat Rev Cardiol 7: 528-536.

19. Lai CF, Seshadri V, Huang K, Shao JS, Cai J, et al. (2006) An osteopontinNADPH oxidase signaling cascade promotes pro-matrix metalloproteinase 9 activation in aortic mesenchymal cells. Circ Res 98: 1479-1489.

20. Bruemmer D, Collins AR, Noh G, Wang W, Territo M, et al. (2003) Angiotensin II-accelerated atherosclerosis and aneurysm formation is attenuated in osteopontin-deficient mice. J Clin Invest 112: 1318-1331.

21. Yao Y, Bennett BJ, Wang X, Rosenfeld ME, Giachelli C, et al. (2010) Inhibition of bone morphogenetic proteins protects against atherosclerosis and vascular calcification. Circ Res 107: 485-494.

22. Berezin AE (2016) Bone-Related Proteins as Markers in Vascular Remodelling In: Biomarkers in Bone Disease: Methods, Discoveries and Applications. Preedy VR (ed.), Springer, Switzerland. 